\title{
Improved Industrial Modeling and Harmonic Mitigation of a Grid Connected Steel Plant in Libya
}

\author{
Abeer Oun $^{1}$, Ibrahim Benabdallah ${ }^{2,}$ Adnen Cherif ${ }^{3}$ \\ Department of Physics, ATEESS, Faculty of Sciences of Tunis \\ University of Tunis EL Manar, Tunisia
}

\begin{abstract}
Currently, we are living in a new transition process towards the fourth phase of industrialization, well known as the purported Industry 4.0. This development backbone supposes a sustainable manufacturing. Were optimal functionalities of a factory components especially energy rationalization and enhanced power quality are nonetheless a privilege but an obligation to introduce efficiently artificial intelligence AI, smart metering SM and automated decision making ADM. In the same axis of mitigating power quality issues, this paper is introduced first to draw innovatively a virtual reality (VR) complex grid connected steel power plant and then to depict harmonic sources in order to moderate them which are caused essentially by nonlinear installed loads manifesting power system quality issues and exhibiting periodic signal distortion. Accordingly, it was essential to assay the diverse origins of harmonic problems and to present the most accommodate and economic solution techniques. Related voltage and current harmonic flows at $30 \mathrm{kV}$ levels, of the General Electricity Company of Libya GECOL located in Tripoli city, are examined. Afterward, inquire jointly their harmful effects on plant components. In order to attenuate distortion, a harmonic analysis has been investigated. Then appropriate filters design have been sized, designed, simulated and appended to the panel. Simulation results are presented and validated using ETAP industrial software under real measurement arena.
\end{abstract}

Keywords-Industry 4.0; distribution systems; THD; harmonic load flow; passive filters

\section{INTRODUCTION}

Over the last few years in developing countries many linkage reinforcement attempts between researchers, industry stakeholders and the socioeconomic world aiming to promote the fourth [1-4] industrial revolution. Engineering researchers have been focusing on power system studies especially after the massive introduction of new renewable energies sources [5 -7] affecting the overall radial electrical system compartments. Power quality issues are generally caused by non-linear loads; corrective operations are not automatically gained with the same action due to devices nature [8-9] and response differences. One of the key ascertainment to gain towards migrating into 4th industrial revolution and enhancing power quality is mitigating harmonic disturbances which come largely from equipment with non-linear current and voltage characteristic causing severe damages on voltage supply network. As real manufacturing domain suffering from harmonic disturbances we quote induction melting furnaces [10] which use electric current to dissolve metal. Where exceeded Harmonic Distortion THD and its moving average
TDD compared to the 519_1992 IEEE Standard can cause overloading of power factor correction, over voltage and extra currents, increased error in energy meters, malfunctions of protective gears, relays, circuit breakers, tripping of machines at smaller loads and inductive interference [11-12] with neighboring electrical grid.

\section{A. Industry 4.0}

Manufacturing industry is ongoing a deep permeating process, where physical and virtual worlds will be fused through Virtual-physical systems. This process is fuelled by high technology enablers like; Smart metering and monitoring Mobile Devices, Internet of Things IOT, Internet of Every Things IOE, Cloud computing, Big Data, 3 D printing ... aiming to achieve the Smart Factory Paradigm. In the same context:

Authors in [13] Provides a review of electrical energy metering state-of-the-art in, with a meticulous focus on energy metering in complex manufacturing establishments. They highlighted quantification and visibility in energy consumption. Where habitually, operation of complex manufacturing facilities planning decisions have been based only on conventional metrics without considering energy consumption rationalization and taking into account its energy standards which ought to be one of the keys of manufacturing strategies as well demonstrating the importance of power quality statistics instance; such as voltage sags and harmonic distortion.

Further in [14], authors offered an overview of different opportunities for sustainable manufacturing in Industry 4.0 in addition to a use case for the upgrading of manufacturing equipment as a specific opportunity for sustainable manufacturing.

In [15], authors underlined the fact that several manufacturing systems are not ready to manage big data due to the lack of smart analytics tools. Management of big data as well as the readiness level of smart predictive informatics tools has been drawn to achieve transparency and productivity.

\section{B. Power System Analysis}

The global growing of nonlinear loads applications, coming mostly from the wide use of power electronic devices, have resulted power quality issues more than ever seen before. Here appears the power System study and analyses as compulsory parts of any power system engineering for quantification query, in this same axis: [16] is an assessment of harmonic disturbances seen in a real smart grid. Then, solution to 
maintain the operation of the distribution photovoltaic system plant and electrical cars within imposed standards PQ limits.

Authors in [17] focused on benefits of the detailed analyses by using ETAP software, which performs several numerical calculations of a huge integrated power system.

\section{THD}

Harmonic analysis, modelling and mitigation new techniques [18] Drawn a lot of ink hereunder we noted some of annexed works.

In [19], authors gave a summary on new design energy conversion system and methods such as Particle Swarm optimization, Genetic Algorithm, and Differential Evolution advantages and limitations.

For the case of [20], a classification of most commonly used methods of power system harmonics estimation reviewed based upon analysis tools and applications type. Diverse harmonics estimation techniques are gathered besides standards, papers and books.

Whereas in [21], the authors investigated harmonic effects on radial distribution grid losses and transmission lines capacities. The presented harmonic assessments have a real harmonic measurement and computer-based system modeling background in local distribution substations with ETAP.

As a consequence, many industrial software tools and new virtual reality approaches modeling and simulation have been performed to assay the grid. Computer based software are leading the revolution in recent advances in electrical and industrial engineering. In our case a mutinous harmonic load flow analyses is performed through ETAP industrial software based on practical measurement and overall on-line monitoring to distinguish the immediate effects of furnaces load on the Point of common coupling PCC. The one line diagram drawing is used to scrutinize the overall power system state from top grid source until the load which is the steel plant. All power components like transformers, CT's, PT's, Furnaces, motors, cables etc.... are exactly modelled thanks to ETAP real ratings library.

This paper represents a novel approach to analyze and monitor the industrial grid connected power system by just using real time software, ETAP. Then, Harmonic analyses of current and voltage waveforms when sinusoidal voltage is applied to a non-linear load like furnaces are made finally the auto-sizing filter feature is presented to mitigate distortion and bring it within standards. Section 2 is the global single line diagram of the system under study; this diagram is implemented based on practical data in ETAP for simulation purpose in Section 3. Section 4 contains analyses which include monitoring of this large power system and harmonic load Flow. Section 5 deals with adopted harmonic solution method. Section 6 is the Conclusion of this research work.

\section{USE DESCRIPTION OF THE FACTORY SUBSTATION}

First of all we propose to introduce the factory substation modeling in Fig. 1 which is fed from $30 \mathrm{kV} / 11 \mathrm{kV}, 20$ MVA transformers inside the factory substation, which, in turn, feeds the Al-Taba substation $30 \mathrm{KV}$ through two overhead transmission lines $30 \mathrm{KV}$.

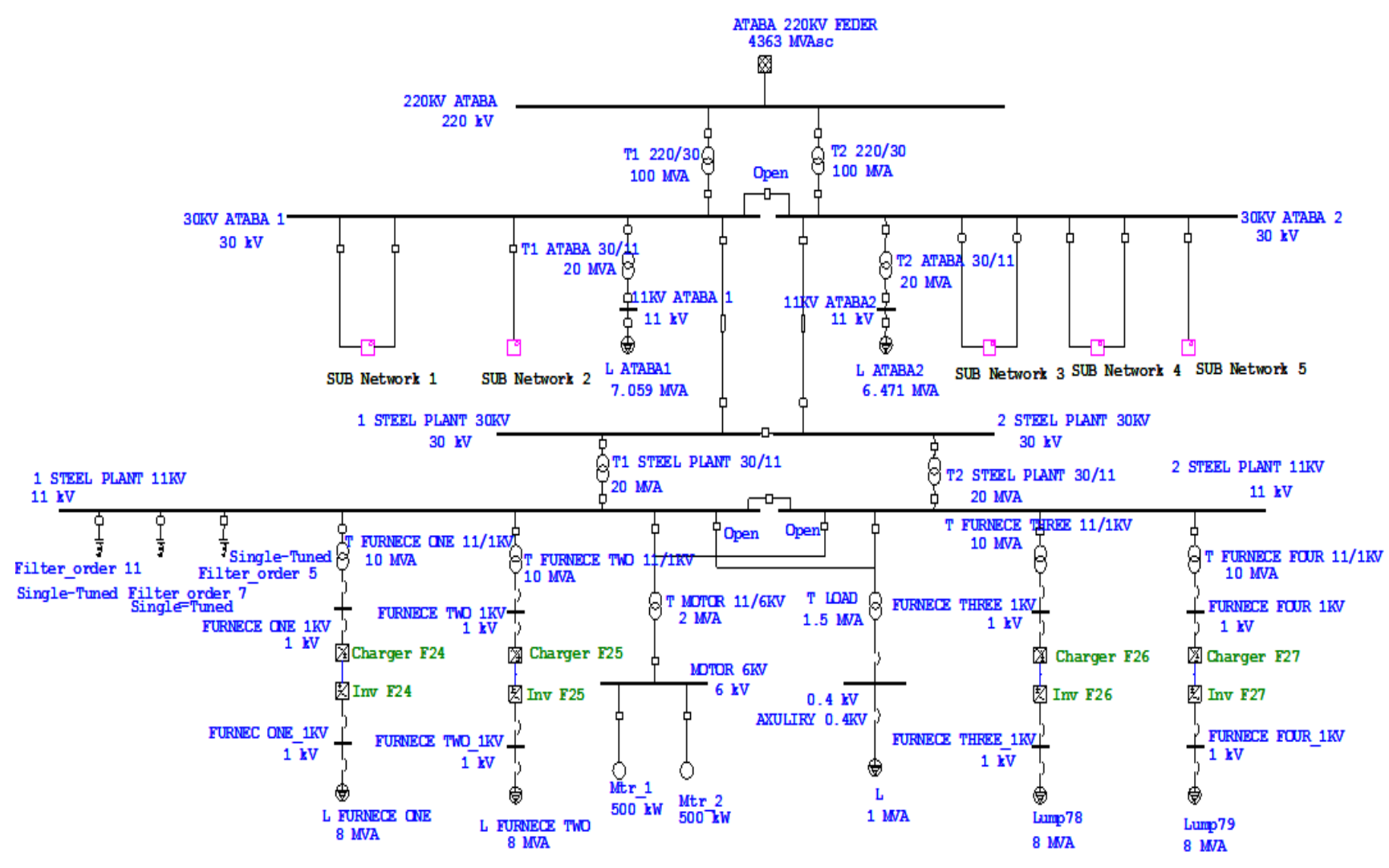

Fig. 1. Overall One Line Diagram Grid Presentation. 


\section{LOAD FLOW ANALYSIS}

Load flow analysis [22] examines the continuous operation of the power system to determine the main operating parameters, especially voltage levels on buses and load levels on power grid elements. It is necessary to study the load flow at the factory maximum loading to ensure that the voltage changes in all buses is conform to the required limits. All transformers, cables and buses are satisfying nominal equipment functionality specifications.

The worst scenario to connect the factory to the Al-Taba substation (30KV) GECOL's Tripoli at the maximum load operation of the factory without taking into account the development of required improvements (power factor correction equipment, use of tap change for in-plant transformers) to determine the full factory operation to find out extent impact and changes on the network (voltage levels, power factor) ensuring the required limits described in [23].

\section{A. First Work Sequence}

The first condition set-up is done by assuming that all factory loads (furnaces, motors, auxiliary loads) are not connected to be sure about highest reachable voltage at all connected buses via Al-Taba substation at $30 \mathrm{KV}$. First notable condition, as shown in Table 1, buses may suffer from high voltage exceeding $5 \%$.

We conclude from Table 1 that the voltage changes are within operational limits $\pm 5 \%$.

\section{B. Second Work Sequence}

The second assumed condition is that all furnaces, motors and auxiliary loads are feed by setting both factory transformers $30 / 11 \mathrm{KV}$ on normal tap change as drawn in Table 2.

We conclude from Table 2 that the voltage doesn't change at maximum factory loading, even with setting up both factory transformers $30 / 11 \mathrm{KV}$ on the normal tap change voltages still are within $\pm 5 \%$ limits in all buses.

TABLE I. The Voltage LeVels at Buses in CASe the Factory is NOT LOADED

\begin{tabular}{|l|l|l|l|l|}
\hline Bus ID & $\begin{array}{l}\text { Nominal } \\
\text { kV }\end{array}$ & $\begin{array}{l}\text { Voltage } \\
\%\end{array}$ & $\begin{array}{l}\text { MW } \\
\text { Loading }\end{array}$ & PF\% \\
\hline 220KV ATABA & 220 & 95 & 79.647 & 83.49 \\
\hline 30KV ATABA 1 & 30 & 100.14 & 38.594 & 83.64 \\
\hline 30KV ATABA 2 & 30 & 100.21 & 41.61 & 87.21 \\
\hline $\begin{array}{l}\text { I STEEL PLANT } \\
\text { 30KV }\end{array}$ & 30 & 100.19 & - & - \\
\hline $\begin{array}{l}\text { 2 STEEL PLANT } \\
\text { 30KV }\end{array}$ & 30 & 100.19 & - & - \\
\hline
\end{tabular}

TABle II. The Voltage LeVels at Buses In CASE the MaXimum FACTORY LOADING

\begin{tabular}{|l|l|l|l|l|}
\hline Bus ID & $\begin{array}{l}\text { Nominal } \\
\text { kV }\end{array}$ & $\begin{array}{l}\text { Voltage } \\
\text { \% }\end{array}$ & $\begin{array}{l}\text { MW } \\
\text { Loading }\end{array}$ & PF\% \\
\hline 220KV ATABA & 220 & 95 & 109.463 & 79.53 \\
\hline 30KV ATABA 1 & 30 & 98.38 & 53.346 & 82.28 \\
\hline 30KV ATABA 2 & 30 & 98.45 & 55.591 & 83.87 \\
\hline $\begin{array}{l}\text { 1 STEEL PLANT } \\
\text { 30KV }\end{array}$ & 30 & 96.33 & 15.305 & 78.32 \\
\hline $\begin{array}{l}\text { 2 STEEL PLANT } \\
\text { 30KV }\end{array}$ & 30 & 96.33 & 14.509 & 74.58 \\
\hline
\end{tabular}

\section{Short Circuit Analysis}

Table 3 hereunder shows the short circuit currents values at the factory and network buses.

TABLE III. ShORT CirCUIT CURRENTS AT FACTORY AND NETWORK BUSES

\begin{tabular}{|l|l|}
\hline Bus & short circuit Current ( KA ) \\
\hline 220KV ATABA & 11.45 \\
\hline 30KV ATABA 1 & 18.2 \\
\hline 30KV ATABA 2 & 18.2 \\
\hline 1 STEEL PLANT 30KV & 15.2 \\
\hline 2 STEEL PLANT 30KV & 15.2 \\
\hline
\end{tabular}

\section{HARMONIC ORIGINS ASSESSMENT}

Mainly harmonic origins in industrial steel systems are classified into three origin types; single and three phase loads, harmonics generated by transformers [24] and harmonics created by induction furnaces [25]. A special interest will be done in this section to fetch and inhibit these issues and eliminate their causes.

First of all, we propose the modeling of induction furnaces conversion chain which are coupled in our case using $11 / 1 \mathrm{kv}$ transformer as drawn in Fig. 2:

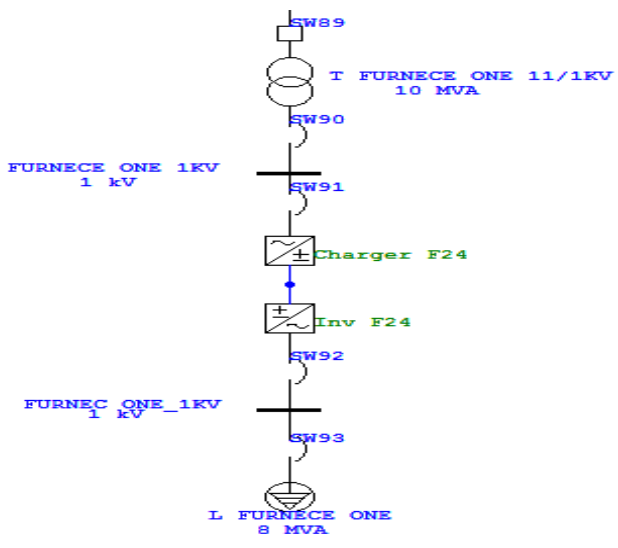

Fig. 2. ETAP Modeling of the Induction Furnace. 
Current and voltage harmonic distortions are measured throughout the factory and the electrical network buses then compared with standards. The point of common coupling (PCC) bus is located at $30 \mathrm{KV}$ level between the factory and the grid; Captured figures below describe the voltage waveform and spectrum at every bus and gave a clear idea of harmonic sources.

Fig. 3 and 4 are describing voltage waveform and its spectrum at Al-Taba $220 \mathrm{KV}$ source bus.

Fig. 5 and 6 are describing voltage waveform and its related spectrum at Al-Taba $30 \mathrm{KV}$ region after stepping it down with the transformer 220/30 KV.

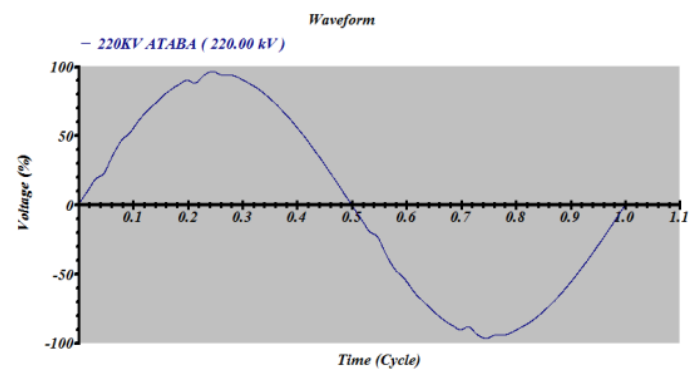

Fig. 3. Waveform for the Voltage at Bus Al-Taba 220KV.

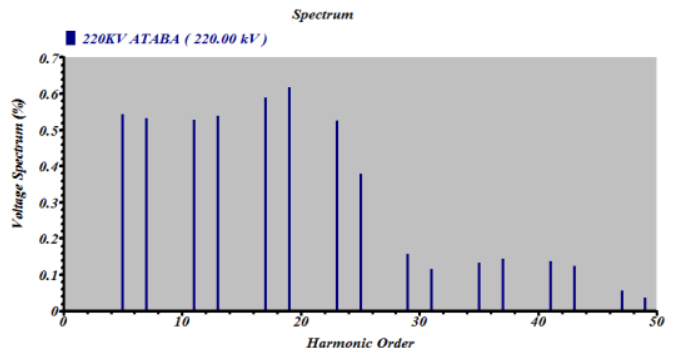

Fig. 4. Spectrum for the Voltage at Bus Al-Taba 220KV.

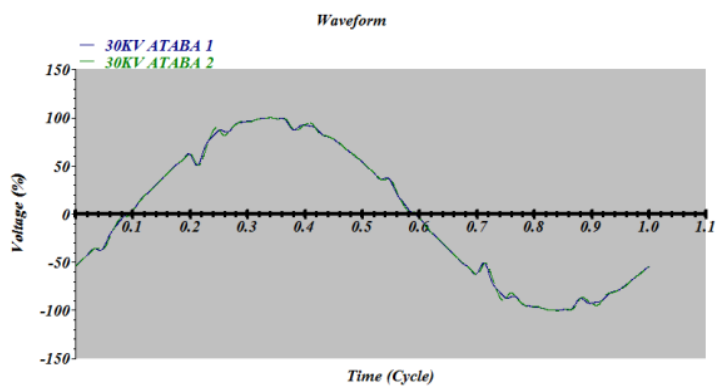

Fig. 5. Voltage Waveform at Al-Taba 30KV Bus.

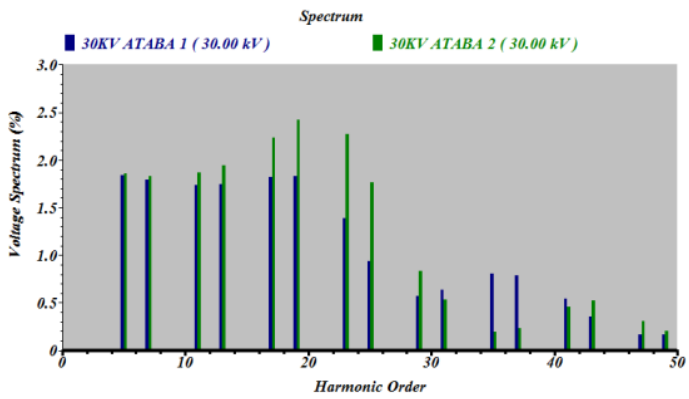

Fig. 6. Voltage Spectrum at Al-Taba 30KV Bus.

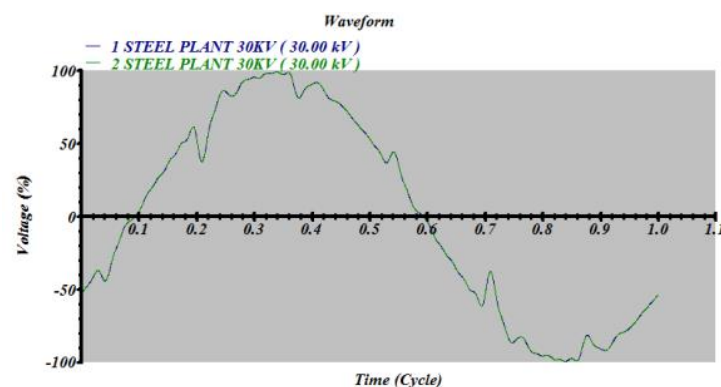

Fig. 7. Voltage Waveform at Steel Plant 30KV Bus.

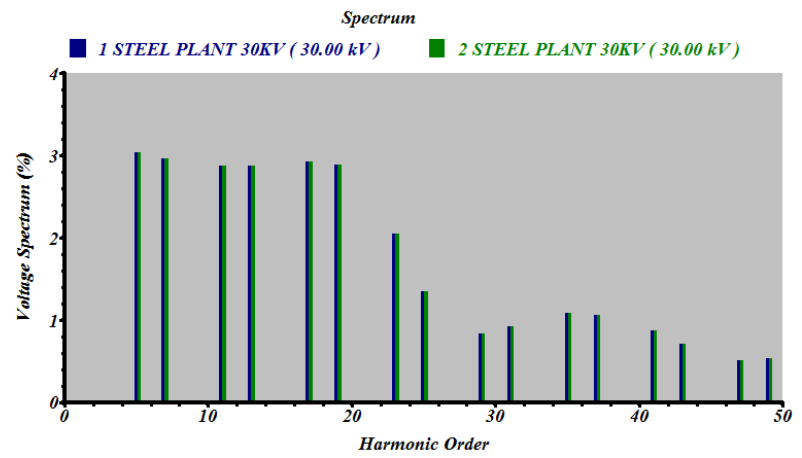

Fig. 8. Voltage Spectrum at Steel Plant 30KV Bus.

Fig. 7 and 8 show voltage waveform and their related spectrum at steel plant bus. We conclude subjectively from voltage curves that induction furnaces loads are mainly the issue maker. As well, Generated harmonics by the induction furnaces impact in turn neighboring grid.

Table 4 mention the voltage distortion levels at the factory and grid buses compared to acceptable standard values.

We notice that VTHD values are slightly out of accepted standard range values explicating waveforms distortions; Stills to essay current waveforms and spectrums for all buses.

Fig. 9 and 10 are describing current waveform and its spectrum at Al-Taba 220/30 KV transformer.

Fig. 11 and 12 are describing current waveform and its spectrum at steel plant 30/11 KV transformer.

TABLE IV. VOLTAGE DisTORTION LEVELS AT THE FACTORY AND NETWORK BUSES

\begin{tabular}{|l|l|l|l|}
\hline Bus Name & $\begin{array}{l}\text { Nominal Voltage } \\
(\text { KV })\end{array}$ & $\begin{array}{l}\text { VTHD } \\
(\%)\end{array}$ & $\begin{array}{l}\text { VTHD Standard } \\
(\%)\end{array}$ \\
\hline 220KV ATABA & 220 & 1.683346 & 1.5 \\
\hline 30KV ATABA 1 & 30 & 5.17991 & 5 \\
\hline 30KV ATABA 2 & 30 & 6.162314 & 5 \\
\hline $\begin{array}{l}\text { 1 STEEL PLANT } \\
\text { 30KV }\end{array}$ & 30 & 8.482183 & 5 \\
\hline $\begin{array}{l}\text { 2 STEEL PLANT } \\
\text { 30KV }\end{array}$ & 30 & 8.482183 & 5 \\
\hline
\end{tabular}




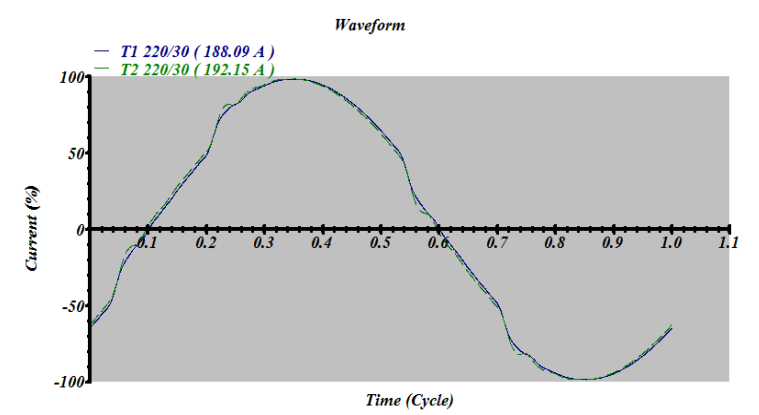

Fig. 9. Waveform for the Current at Al-Taba Transformer 220/30KV.

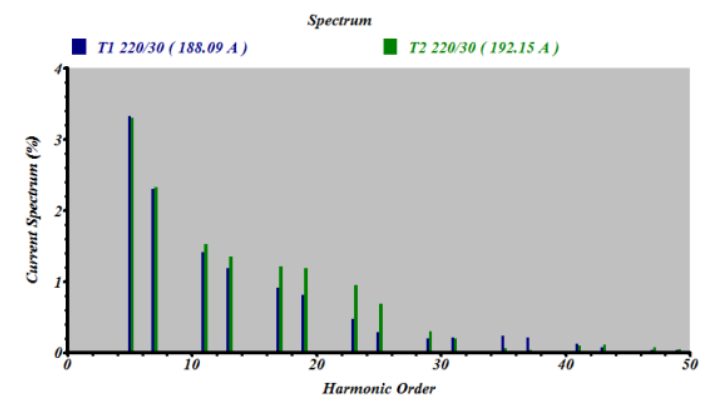

Fig. 10. Spectrums for the Current at Al-Taba Transformer 220/30KV.

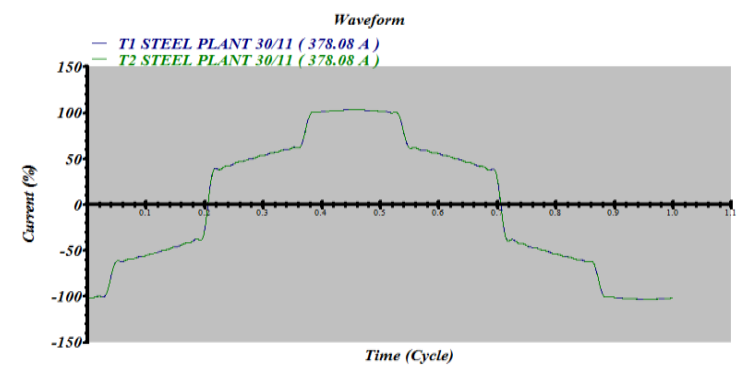

Fig. 11. Waveform for the Current at Steel Plant Transformer 30/11KV.

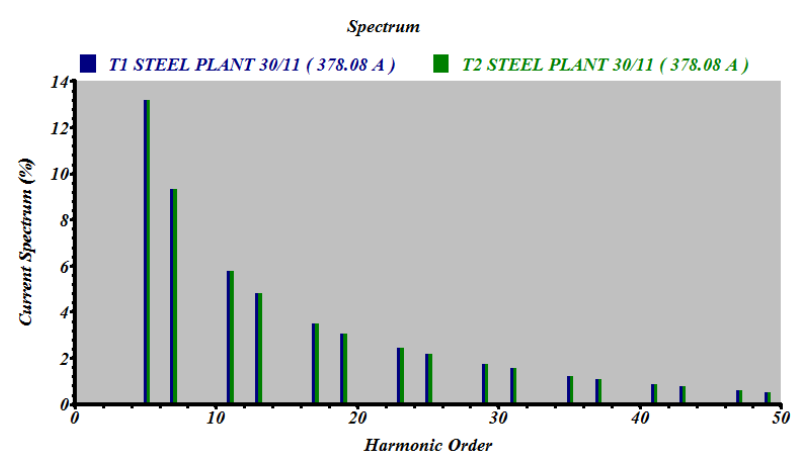

Fig. 12. Spectrums for the Current at Steel Plant Transformer 30/11KV.

Indeed, we prove objectively that the main source of grid distortion is induction furnaces loads, due to generated harmonics through transformers current, which in turn impact grid elements. Table 5 declares the current distortion levels at overall factory, network buses and compared them to acceptable standard values.

We notice that some buses are out of ITHD allowable ranges. Table 6 summarizes the odd harmonic currents $(5,7$, 11, and 13) at steel plant PCC.
TABLE V. CURRENT Distortion LEVELS AT THE FACTORY AND NETWORK BUSES

\begin{tabular}{|c|c|c|c|}
\hline Bus & & ITHD (\%) & $\begin{array}{l}\text { ITHD } \\
\text { Standard } \\
(\%)\end{array}$ \\
\hline From Bus ID & To Bus ID & & \\
\hline \multirow[t]{2}{*}{ 220KV ATABA } & 30KV ATABA 1 & 4.891303 & 12 \\
\hline & 30KV АTABA 2 & 5.211092 & 12 \\
\hline \multirow[t]{2}{*}{ 30KV ATABA 1} & 220KV ATABA & 5.319292 & 5 \\
\hline & $\begin{array}{l}\text { 1 STEEL PLANT } \\
\text { 30KV }\end{array}$ & 21.00901 & 8 \\
\hline \multirow[t]{3}{*}{ 30KV ATABA 2} & 220KV ATABA & 5.667062 & 5 \\
\hline & $\begin{array}{l}2 \text { STEEL PLANT } \\
\text { 30KV }\end{array}$ & 20.91081 & 8 \\
\hline & STEEL PLANT(PCC) & & \\
\hline \multirow[t]{2}{*}{$\begin{array}{l}1 \text { STEEL } \\
\text { PLANT 30KV }\end{array}$} & 30KV ATABA 1 & 19.90503 & 8 \\
\hline & $\begin{array}{l}1 \text { STEEL PLANT } \\
11 \mathrm{KV}\end{array}$ & 19.8123 & 8 \\
\hline \multirow{2}{*}{$\begin{array}{l}2 \text { STEEL } \\
\text { PLANT 30KV }\end{array}$} & 30KV ATABA 2 & 20.02313 & 8 \\
\hline & $\begin{array}{l}2 \text { STEEL PLANT } \\
11 \mathrm{KV}\end{array}$ & 19.8123 & 8 \\
\hline
\end{tabular}

TABLE VI. CURRENT ODD HARMONICS (...., 5, 7, 11, 13), FOR THE FACTORY TRANSFORMERS (1\&2) AT 30KV

\begin{tabular}{|l|l|}
\hline Order & Mag \% \\
\hline $\mathbf{5}$ & 13.87 \\
\hline $\mathbf{7}$ & 9.80 \\
\hline $\mathbf{1 1}$ & 6.03 \\
\hline $\mathbf{1 3}$ & 4.99 \\
\hline $\mathbf{1 7}$ & 3.61 \\
\hline $\mathbf{3 1}$ & 1.50 \\
\hline $\mathbf{3 5}$ & 1.16 \\
\hline $\mathbf{3 7}$ & 1.013 \\
\hline $\mathbf{4 7}$ & 0.48 \\
\hline $\mathbf{4 9}$ & 0.40 \\
\hline
\end{tabular}

\section{AdOPTED HARMONIC Mitigation Method}

Harmonic filters [26] are used to reduce the distortion in voltage and current waveforms by controlling the flow of harmonic currents to reach acceptable standard levels of distortion in voltage and current waveforms.

There are several types of used harmonic filters to reduce THD and compensate the reactive power.

Among these filters passive filters, active filters, 12 pulse rectifiers, 18 pulse rectifiers ....and active front end (AFE) drives which are cited in order form complexity, efficiency and performance point of view. In fact, sophisticated mitigation techniques are not widely used in industry like passive filters due to their effectively high cost and complex control techniques. Our strategy was to achieve best results with 
minimum of cost and implementation complexity depending of the industrial customer budget and fair obtained results.

\section{A. Passive Filter Design using ETAP}

ETAP provides an auto-sizeable modeling feature of filters as shown in Fig. 13 hereunder:

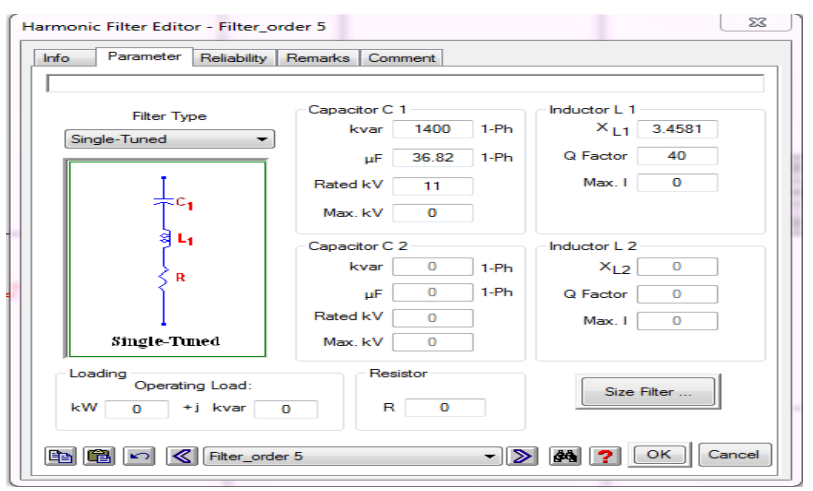

Fig. 13. Modeling Passive Filters (Single Tuned Filter).

\section{B. The Parameters Calculation of the Single Tuned Filter}

Table 7 illustrates ( R, L, and C) parameters for selected used filters frequencies at 5 th, 7 th and 11th harmonic orders.

TABLE VII. THE PARAMETERS OF THE FILTERS OF THE $5^{\text {TH }}, 7^{\text {TH }}$ AND $11^{\text {TH }}$ HARMONIC ORDER

\begin{tabular}{|l|l|l|l|}
\hline Order & 5th & 7th & 11th \\
\hline QC(KVAR/ 1Ph) & 1400 & 1400 & 1400 \\
\hline C( $\boldsymbol{\mu F / ~ 1 P h ) ~}$ & 36.82 & 36.82 & 36.82 \\
\hline VC KV (ASUM) & 23.394 & 19.52 & 17.118 \\
\hline XL(Ohm/1Ph at 50HZ) & 3.4581 & 1.7643 & 0.7145 \\
\hline L(mH/1Ph) & 11.01 & 5.62 & 2.27 \\
\hline IL A (RMS) & 322.5 & 245.6 & 181.8 \\
\hline Q Factor & 40 & 40 & 40 \\
\hline R(Ohm/1Ph) & 0.4323 & 0.3088 & 0.1965 \\
\hline
\end{tabular}

\section{Results with Filters}

Load flow calculations were performed after harmonic filters introduction to improve voltage levels, rectify power factor and omit undesirable harmonics. Moreover, there are two assumed simulation sequences:

The first sequence is all factory loads (furnaces, motors, auxiliary loads) are disconnected except operational filters at Al-Taba substation 30KV. Results are shown in Table 8.

In the second sequence we reconnect all furnaces, motors and auxiliary loads with filters by setting the two transformers $30 / 11 \mathrm{KV}$ of the factory on normal tap change. Furthermore setting the $11 / 1 \mathrm{KV}$ level 4 transformers on the 5\% tap change, $11 / 6 \mathrm{KV}$ transformer on $2.5 \%$ tap change and the $11 / 0.4 \mathrm{KV}$ transformer on $3.75 \%$ tap change.

The load flow results show a clear improvement in voltage levels at all buses as shown in Table 9.
TABLE VIII. The Voltage LeVELS AT BUSES IN CASE THE FACTORY IS NOT LOADED AFTER FILTERS

\begin{tabular}{|l|l|l|l|l|}
\hline Bus ID & $\begin{array}{l}\text { Nominal } \\
\text { kV }\end{array}$ & $\begin{array}{l}\text { Voltag } \\
\text { e }\end{array}$ & $\begin{array}{l}\text { MW } \\
\text { Loading }\end{array}$ & PF\% \\
\hline 220KV ATABA & 220 & 95 & 79.661 & 90.29 \\
\hline 30KV ATABA 1 & 30 & 100.98 & 38.628 & 83.73 \\
\hline 30KV ATABA 2 & 30 & 101.05 & 41.588 & 87.75 \\
\hline $\begin{array}{l}\text { 1 STEEL PLANT } \\
\text { 30KV }\end{array}$ & 30 & 101.68 & 0.824 & 10.58 \\
\hline $\begin{array}{l}\text { 2 STEEL PLANT } \\
\text { 30KV }\end{array}$ & 30 & 101.68 & 0.808 & 11.66 \\
\hline
\end{tabular}

TABLE IX. Buses Voltage LeVELS AFter IMPLEMENTING Filters

\begin{tabular}{|l|l|l|l|l|}
\hline Bus ID & $\begin{array}{l}\text { Nominal } \\
\text { kV }\end{array}$ & $\begin{array}{l}\text { Voltage } \\
\%\end{array}$ & $\begin{array}{l}\text { MW } \\
\text { Loading }\end{array}$ & PF\% \\
\hline 220KV ATABA & 220 & 95 & 109.111 & 84.75 \\
\hline 30KV ATABA 1 & 30 & 99.24 & 53.211 & 87.13 \\
\hline 30KV ATABA 2 & 30 & 99.31 & 55.44 & 88.49 \\
\hline $\begin{array}{l}\text { 1 STEEL PLANT } \\
\text { 30KV }\end{array}$ & 30 & 97.89 & 15.258 & 94.09 \\
\hline $\begin{array}{l}\text { 2 STEEL PLANT } \\
\text { 30KV }\end{array}$ & 30 & 97.89 & 14.464 & 91.63 \\
\hline
\end{tabular}

Fig. 14 to 19 below have shown the waveform and spectrum for the voltage at all buses after connecting the filters.

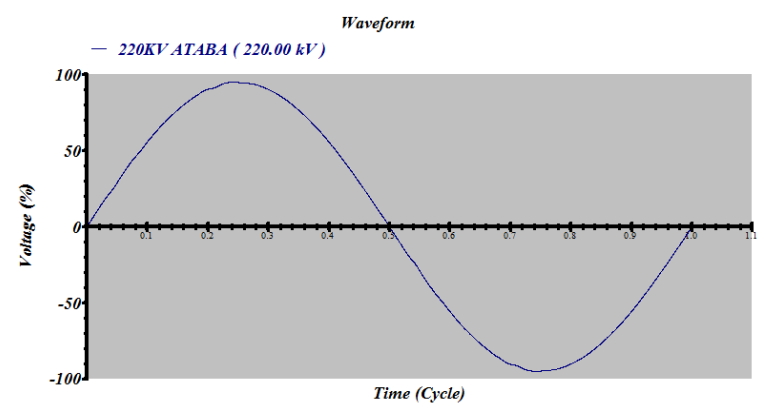

Fig. 14. Voltage Waveform at Bus Al-Taba 220KV with Filters.

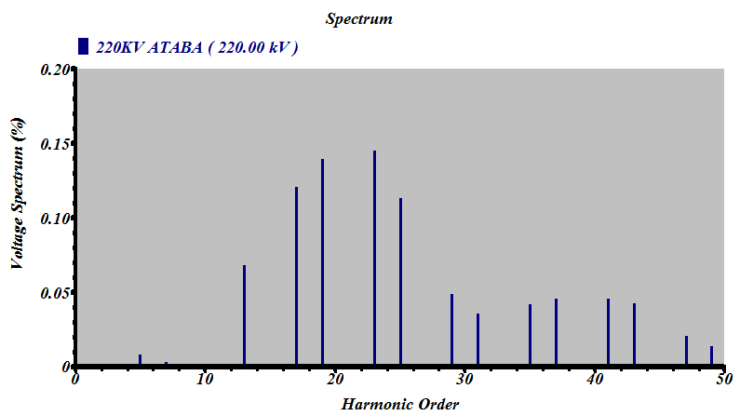

Fig. 15. Voltage Spectrum at Bus Al-Taba 220KV with Filters. 


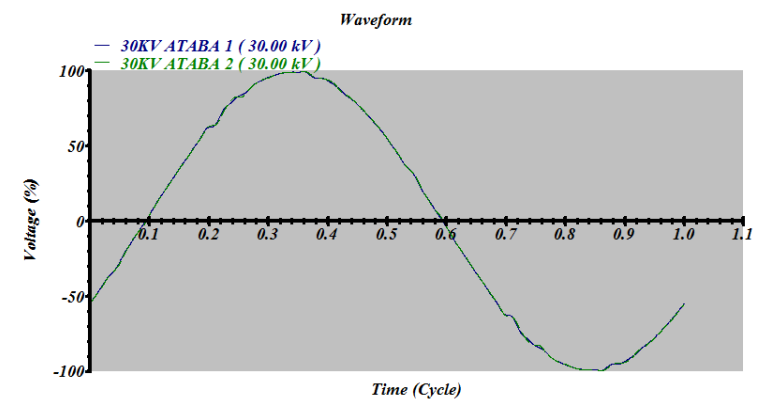

Fig. 16. Voltage Waveform at Al-Taba 30KV Bus with Filters.

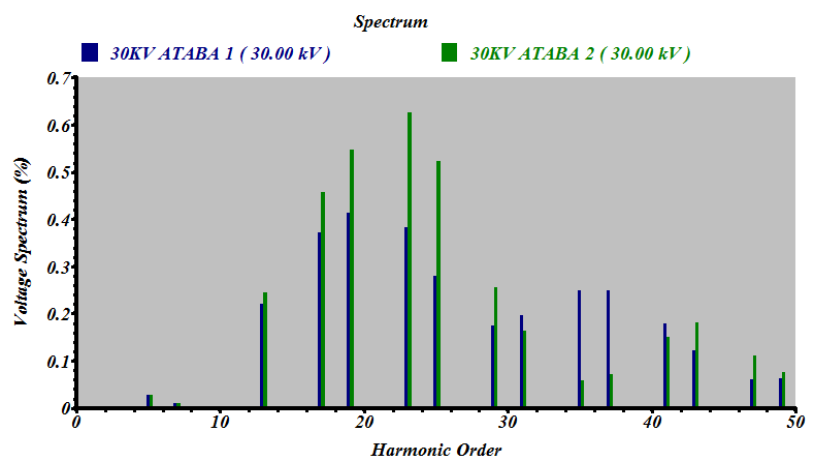

Fig. 17. Voltage Spectrum at Al-Taba 30KV Bus with Filters.

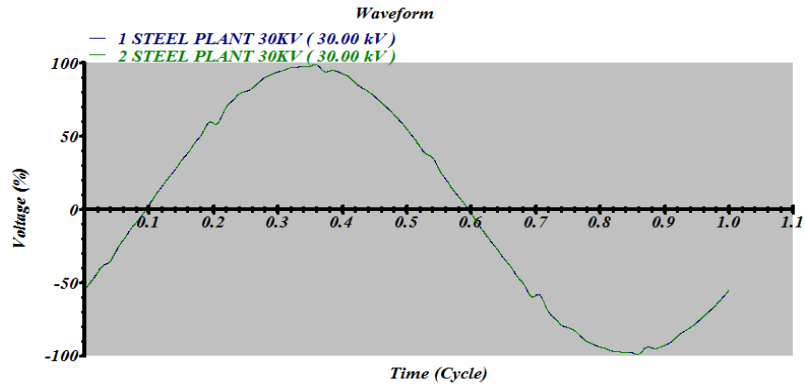

Fig. 18. Voltage Waveform at $30 \mathrm{KV}$ Steel Plant Bus with Filters.

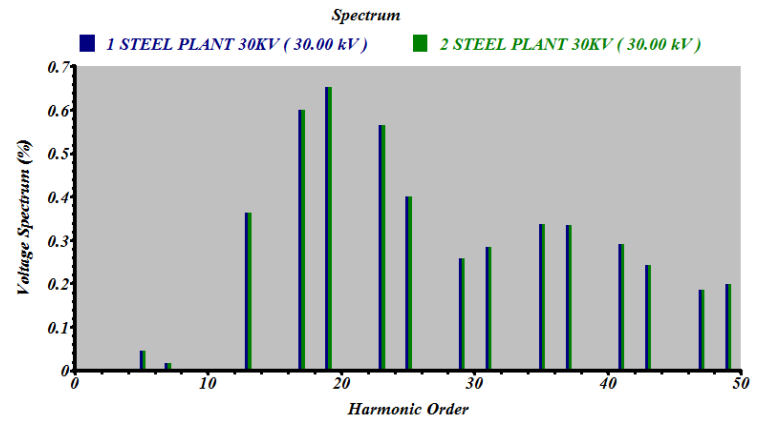

Fig. 19. Voltage Spectrum at Steel Plant 30KV Bus with Filters.

Table 10 is the results comparison with standard limits after connecting the passive filters on PCC.

Fig. 20 to 25 show the current waveforms and spectrums for all buses after connecting the filters.

Table 11 shows the current distortion levels compared with standard values after connecting passive filters at PCC. The current distortion levels at all buses are acceptable and within standard limits.
TABLE $X$. THE VOLTAGE Distortion LeVELS AT THE FACTORY AND NETWORK BUSES WITH FILTERS

\begin{tabular}{|l|l|l|l|}
\hline Bus ID & Nominal kV & VTHD \% & $\begin{array}{l}\text { VTHD } \\
\text { \%Standard }\end{array}$ \\
\hline 220KV ATABA & 220 & 0.31 & 1.50 \\
\hline 30KV ATABA1 & 30 & 0.92 & 5.00 \\
\hline 30KV ATABA2 & 30 & 1.20 & 5.00 \\
\hline $\begin{array}{l}\text { 2STEEL } \\
\text { PLANT30KV }\end{array}$ & 30 & 1.44 & 5.00 \\
\hline
\end{tabular}

Table 12 shows the content of current odd harmonics $(5,7$, 11, and 13) at PCC steel plant bus $30 \mathrm{KV}$

Comparing before and after states we notice that voltage magnitudes are between $95 \%$ and $105 \%$ at all buses. THDi and THDv values are acceptable compared with the standard limits after filters introduction. As well as, our criterion; which was from the beginning to achieve the most suitable results with lowest implementation cost and fastest implementation technology, respecting the industrial customer requirements.

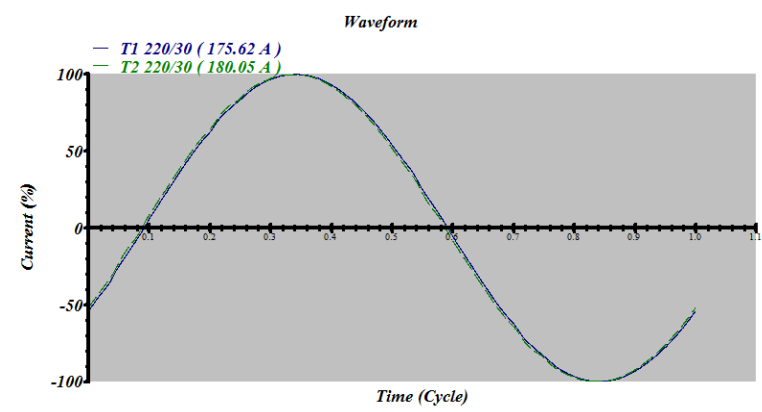

Fig. 20. Current Waveform at Al-Taba Transformer 220/30KV with Filters.

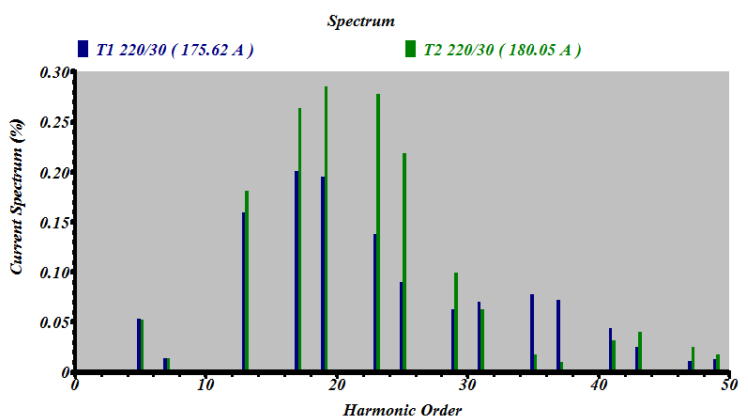

Fig. 21. Current Spectrum at Al-Taba Transformer 220/30KV with Filters.

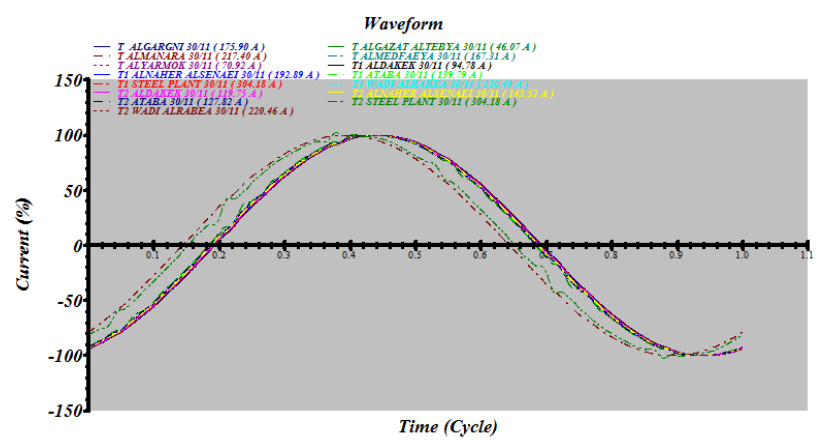

Fig. 22. Current Waveforms at All Transformer 30/11KV with Filters. 


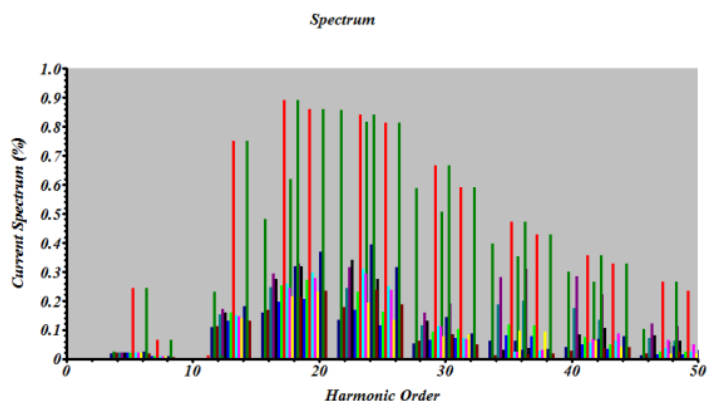

Fig. 23. Current Spectrums at All Transformer 30/11KV with Filters.

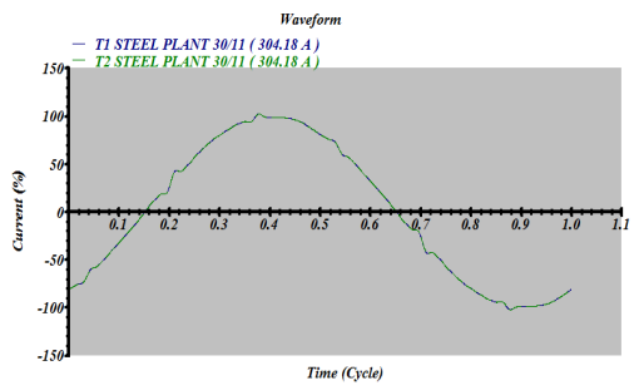

Fig. 24. Current Waveform at Steel Plant Transformer 30/11KV with Filters.

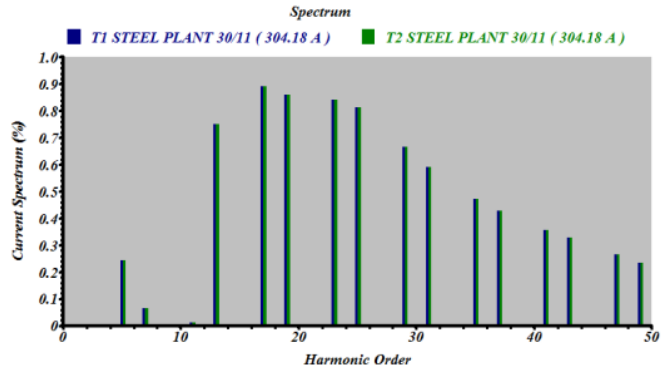

Fig. 25. Current Spectrum at Steel Plant Transformer 30/11KV with Filters.

TABLE XI. C CURRENT DistORTION LEVELS AT THE FACTORY AND NETWORK BUSES WITH FILTERS

\begin{tabular}{|c|c|c|c|}
\hline From Bus ID & To Bus ID & $\begin{array}{l}\text { ITHD } \\
(\%)\end{array}$ & $\begin{array}{l}\text { \%ITHD } \\
\text { Standard }\end{array}$ \\
\hline \multirow{2}{*}{ 220KV ATABA } & 30KV ATABA 1 & 0.40 & 12 \\
\hline & 30KV ATABA 2 & 0.57 & 12 \\
\hline \multirow[b]{2}{*}{ 30KV ATABA 1} & 220KV ATABA & 0.43 & 5 \\
\hline & $\begin{array}{l}\text { 1 STEEL PLANT } \\
\text { 30KV }\end{array}$ & 2.35 & 8 \\
\hline \multirow{2}{*}{ 30KV ATABA 2} & 220KV ATABA & 0.62 & 8 \\
\hline & $\begin{array}{l}\text { 2STEEL PLANT } \\
\text { 30KV }\end{array}$ & 3.02 & 8 \\
\hline \multicolumn{4}{|c|}{ STEEL PLANT (PCC) } \\
\hline \multirow{2}{*}{$\begin{array}{l}\text { 1STEEL PLANT } \\
\text { 30KV }\end{array}$} & 30KV ATABA 1 & 1.98 & 8 \\
\hline & $\begin{array}{l}\text { 1 STEEL PLANT } \\
11 \mathrm{KV}\end{array}$ & 2.26 & 8 \\
\hline \multirow{2}{*}{$\begin{array}{l}\text { 2STEEL PLANT } \\
\text { 30KV }\end{array}$} & 30KV ATABA 2 & 2.86 & 8 \\
\hline & $\begin{array}{l}\text { 2STEEL PLANT } \\
11 \mathrm{KV}\end{array}$ & 2.26 & 8 \\
\hline
\end{tabular}

TABLE XII. CONTENT OF THE ODD HARMONICS OF THE CURRENT (.., 5, 7, 11,13 FACTORY TRANSFORMERS ( $1 \& 2$ ) AT 30KV WITH FILTERS

\begin{tabular}{|l|l|}
\hline Order & \%Mag \\
\hline $\mathbf{5}$ & 0.24 \\
\hline $\mathbf{7}$ & 0.06 \\
\hline $\mathbf{1 1}$ & 0.01 \\
\hline $\mathbf{1 3}$ & 0.75 \\
\hline $\mathbf{1 7}$ & 0.89 \\
\hline $\mathbf{3 1}$ & 0.59 \\
\hline $\mathbf{3 5}$ & 0.47 \\
\hline $\mathbf{3 7}$ & 0.43 \\
\hline $\mathbf{4 7}$ & 0.27 \\
\hline $\mathbf{4 9}$ & 0.23 \\
\hline
\end{tabular}

\section{CONCLUSION}

The harmonic distortions in steel factories are manifesting a big power quality mile stone concern inevitable to eradicate in order to meet the 4.0 industry requirements from power quality enhancement point of view. In the present paper a rigorous THD analyses has been underlined. Furthermore, THDV at PCC initially was measured $8.48 \%$ and the total harmonic current distortion THDI at same bus was $19.81 \%$. A passive filter was proposed to improve harmonic distortion caused by factory components. The results showed an interesting improvement with passive filters operation in THDV which decreases to $1.44 \%$ and $2.26 \%$ THDI without using complex and pricey methods like active filters $12,18 \ldots$ pulse rectifiers and variable frequency drives VDFs like active front end (AFE) drives. As a future work we propose a comparative study between the last cited mitigation techniques.

\section{REFERENCES}

[1] Shiyong Wanga, Jiafu Wana, Daqiang Zhang, DiLi, Chunhua Zhang, Towardssmartfactory for industry 4.0: a self-organized multi-agent system with big data based feedback and coordination, Elseiver, Computer Networks, 101, pp.158-168, 2016

[2] Stephan Weyer, Mathias Schmitt, Moritz Ohmer, Dominic Gorecky, Toward Indusstry 4.0-Standardization as the crucial challenge for highly modular, multivendor production systems, Elseiver, IFACPapersOnLine, 48, 3, pp. 579-584, 2015

[3] Francisco Almada-Lobo, The Industry 4.0 revolution and the future of Manufacturing Execution Systems (MES, Journal of Innovation Management JIM, 3, 4, pp.16-21, 2015

[4] Pai ZHENG, Honghui WANG, Zhiqian SANG, Ray Y. ZHONG, Yongkui LIU, Chao LIU, Khamdi MUBAROK, Shiqiang YU, Xun XU, Smart manufacturing systems for Industry 4.0: Conceptual framework, scenarios, and future perspectives, Springer, Front. Mech. Eng., 13(2), pp137-150, 2018

[5] Foad H. Gandoman, Abdollah Ahmadi, Adel M. Sharaf, Pierluigi Siano, Josep Pou, Branislav Hredzak, Vassilios G. Agelidis, Review of FACTS technologies and applications for power quality in smart grids with renewable energy systems, Renewable and Sustainable Energy Reviews 82 (2018), pp. 502-514, 2018

[6] Selcuk Sakar, Murat E. Balci, Shady H.E. Abdel Aleem, Ahmed F. Zobaa, Integration of large- scale PV plants in non-sinusoidal environments: Considerations on hosting capacity and harmonic distortion limits, Elsevier, Renewable and Sustainable Energy Reviews, 82 (2018), pp. 176-186, 2018

[7] Zunaib Ali, Nicholas Christofides, Lenos Hadjidemetrioub, Elias Kyriakides, A new MAF based $\alpha \beta$ EPMAFPLL for grid connected RES with improved performance under grid faults, Elsevier, Electric Power Systems Research, 154 (2018), pp. 130-139, 2018] 
[8] Muhammad Naveed Malik, Ateeb Iftikhar Toor and Muhammad Asim Siddiqui," load flow analysis of an eht network using ETAP, Journal of Multidisciplinary Engineering Science and Technology, 2016.

[9] C. Barbulesc, St Kilyeni, G. Vuc I. Borlea, Electric substation ancillary services power supply using fuel cell, International Review on Modelling and simulations, volume 4 issue 5,pp.2334-2341,2011

[10] Rana A. Jabbar Khan, Muhammad Junaid and Muhammad Mansoor Asgher," Analyses and Monitoring of $132 \mathrm{kV}$ Grid using ETAP Software",IEEE, ELECO 2009.

[11] C. Barbulescu, St. Kilyeni, N. Chiosa, D. Jigoria-Oprea, Electric substation ancillary services power consumption and quality monitoring and analysis, International Review of Electrical Engineering, volume 6, issue 4, 2011, pp. 2048-2058.].

[12] D. Toader, C. Blaj, St. Haragus, Electrocution danger evaluation for broken and grounded conductor, Proceedings of the IEEE International Conference on Computer as a Tool Eurocon 2007 Warsaw, Poland, 2007.

[13] Eoin O’Driscoll, Garret E. O’Donnell, Industrial power and energy metering ea state-of-the-art review, Elsevier, Journal of Cleaner Production, 41 53-64, 2013

[14] T. Stock, G. Seliger, Opportunities of Sustainable Manufacturing in Industry 4.0, Elseiver, Procedia CIRP, 13th Global Conference on Sustainable Manufacturing - Decoupling Growth from Resource Use, $40536-54,2016$

[15] Jay Lee, Behrad Bagheri, Hung-An Kao, Recent Advances and Trends of Cyber-Physical Systems and Big Data Analytics in Industrial Informatics, Proceeding of Int. Conference on Industrial Informatics (INDIN), 2014

[16] Oana CEAKI, George SERITAN, Ramona VATU, Monica MANCASI, Analysis of Power Quality improvement in Smart Grids, THE 10th INTERNATIONAL SYMPOSIUM ON ADVANCED TOPICS IN ELECTRICAL ENGINEERING March 23-25, Bucharest, Romania, 2017
[17] Sneha Kulkarni, Sunil Sontakke, Power System Analysis of a Microgrid using ETAP, International Journal of Innovative Science and Modern Engineering (IJISME), Volume-X, Issue-X, 2015

[18] A. Kalair, N. Abas, A.R. Kalair, Z. Saleem, N. Khan, Review of harmonic analysis, modeling and mitigation techniques, Elsevier, Renewable and Sustainable Energy Reviews, 78, pp. 1152-1187, 2017

[19] Abdul Moeed Amjad, Zainal Salam, A review of soft computing methods for harmonics elimination PWM for inverters in renewable energy conversion systems, Renewable and Sustainable Energy Reviews, 33, pp. 141-153, 2014

[20] Sachin K. Jain, S.N. Singh, Harmonics estimation in emerging power system: Key issues and challenges, Elseiver, Electric Power Systems Research, 81, pp. 1754-1766, 2011

[21] F. Husnayain, N. D. Purnomo, R. Anwar, I. Garniwa, Harmonics Mitigation for Offshore Platform Using Active Filter and Line Reactor Methods, 2014 IEEE International Conference on Electrical Engineering and Computer, Bali, Indonesia, Science24-25 November 2014

[22] H.E. Mazin, Xu Wilsun, Huang Biao, "Determining the harmonic impacts of multiple harmonic producing loads", IEEE Transactions on Power Delivery, vol. 26, issue 2, pp. 1187-1195, 2011.

[23] B. Singh, V. Verma, A. Chandra, K. Al-Haddad, "Hybrid filters for power quality improvement", IEE Proceedings on Generation, Transmission and Distribution, vol. 152, no. 3, pp. 365-378, 2005.

[24] A. Pavas, H. Torres-S Jnchez, A. Delgadillo, "A novel approach for the simulation of power quality stationary disturbances in electric power systems", Proceedings of the 14th International Conference on Harmonics.

[25] Vasirani M, Kota R, Cavalcante RLG, Ossowski S, Jennings NR. An agent-based approach to virtual power plants of wind power generators and electric vehicles. IEEE Trans Smart Grid 2013; 4:1314-22

[26] Arslan O, Karasan OE. Cost and emission impacts of virtual power plant formation in plug-in hybrid electric vehicle penetrated networks. Energy 2013; 60:116-24 